\title{
Numerical and Experimental Research on Hydraulically Generated Noise of a Regenerative Automotive Fuel Pump
}

\author{
Ji-Fu Wang, Hui-Hua Feng, Yong-Xuan Huang, and Xiao-Long Mou
}

\begin{abstract}
Regenerative pumps are receiving increasing interest in industry because of their low cost, low-specific speed, compactness and ability to deliver high heads with stable performance. However, the regenerative pump used in automotive is facing a noise problem. To understand the mechanism in detail, Computational Fluid Dynamics (CFD) and Computational Acoustic Analysis (CAA) together were used to understand the fluid and acoustic characteristics of the fuel pump. The fluid dynamic characteristics of the regenerative fuel pump were investigated numerically using three-dimensional steady and unsteady Reynolds-averaged Navier-Stokes analysis with a shear stress transport turbulence model in ANSYS-CFX 15.0. After the CFD model was validated by the mass flow rate from experiment, the pump inner wall pressure fluctuations extracted from the unsteady flow calculation were used to implement acoustic analysis using finite/boundary element method, vibration-acoustic coupling method and Automatically Matched Layer (AML) method in LMS Virtual. Lab Rev12. Comparing the computational and experimental results shows that sound pressure levels at the observer position are consistent at high frequencies, especially at blade passing frequency.
\end{abstract}

Index Terms-Regenerative pump, pressure fluctuation, dipole, BPF noise.

\section{INTRODUCTION}

Regenerative pumps have found applications in many industrial areas which require high heads at low flow rates including automotive and aerospace fuel pumping, booster systems, water supply, agricultural industries, shipping and mining, and chemical and food processing systems [1]. The fluid and NVH characteristics of regenerative fuel pump need more attention simultaneously. Both vibrations and noise can affect the regenerative pump performance and its life. In regenerative pumps, the sources of vibrations and noise may lie in hydraulic or mechanical aspects' but under normal operating condition, the blade passing frequency is the most usual excitation of vibrations and noise. This frequency results from the nonuniformity of the flow at the impeller outlet which is caused by the effects of the rotor-stator interaction. Many researchers have investigated the fluid performance of regenerative pump in theoretical, numerical and experimental methods.

Theoretically and numerically, Badami [2] presented a hypothesis for evaluating the circulatory flow rate and based his theory on considering the centrifugal force field in the

Manuscript received July 14, 2016; revised January 5, 2017

Ji-Fu Wang, Hui-Hua Feng, and Xiao-Long Mou are with School of Mechanical Engineering, Beijing Institute of Technology, Beijing, China (e-mail: wjfbit@163.com, fenghh@bit.edu.cn, mxlzhenzhu@163.com).

Yong-Xuan Huang is with Chongqing Changan Automobile Co., Ltd, China (e-mail: hyxx92@126.com). side-channel and in the impeller vane grooves. He used momentum exchange theory to predict head-flow curves and compared theoretical and experimental data. Subsequently, Engeda [3] and Song et al. [4] developed a modified theoretical model that can explain the change in the circulatory velocity caused by the variation in channel area Several loss models were assumed by the authors and the results of predictions were compared with experimental and CFD data. Raheel [5] proposed a mathematical model to predict the performance of Delphi automotive fuel pump. Excellent agreement between theoretical and experimental data was observed at the design point. Yoo et al. [6] presented equations to calculate the geometry of rotating flows. They developed an improved mathematical model to suggest systematic methods to find the circulatory flow rate, mean inlet and outlet radii of the impeller, and slip factor. Quail et al. [7] numerically modeled the flow field of a regenerative pump in a manner that had not been achieved previously. The pump performance was numerically assessed without the need of a linear region factor or other data from the experiments conducted on regenerative pumps by using a physically valid geometry model and by resolving the circulatory velocity in the peripheral direction. Karanth et al. [8] presented an approach of Computational Fluid Dynamics (CFD) for simulating and analyzing the flow field within a regenerative pump and validation study of the CFD results with the experimental work, they concluded that the number of impeller vanes and splitter vane at the exit chamber would contribute significantly in terms of static pressure rise across the pump.

Depending on the experimental investigation, Hübel et al. [9] conducted a visualization of three-dimensional flow by using the laser light sheet technique in combination with digital image processing. They studied the influence of vane angles of $45^{\circ}, 60^{\circ}$ and $90^{\circ}$ on the performance of regenerative pump. It was also concluded that the vane angle 45 degree has the best efficiency from other studied angles. Choi et al [10] studied the effect of inclined blade angles of $0^{\circ}, \pm 15^{\circ}, \pm 30^{\circ}$ and $\pm 45^{\circ}$, and radial chevron impellers with chevron angles of $15^{\circ}, 30^{\circ}$ and $45^{\circ}$ on the optimization of regenerative pump performance. Among all blade configurations tested in their study, the chevron blade angle of around $30^{\circ}$ exhibited the highest head with reasonably good efficiency. Mekhail et al. [11] experimentally studied a regenerative blower system with impellers of different inlet blade angles of $90^{\circ}, 115^{\circ}$, $125^{\circ}$ and $135^{\circ}$. The experimental results showed that the pressure head and the efficiency depended strongly on the blade inlet and outlet flow angles as well as on the blade geometry, and that the best blower performance could be obtained at an inlet flow angle of $125^{\circ}$ confirmed by CFD 
simulation analysis. In certain fuel pump module application, Rossetti et al. [12] detected an excessive noise level around the blade passing frequency on test bench, and designed a group of experiments to find the reason, the experimental results showed that the failure was related just to a flow noise. They optimized the noise level through modifying the feed tube. Heo et al. [13] performed a multi-objective optimization to simultaneously enhance the aerodynamic and aeroacoustic performance of a side channel-type regenerative blower. Three arbitrarily selected optimum designs of the regenerative blower increased more significantly in efficiency and decreased in sound pressure level than in a reference design.

Most previous studies focused on the fluid dynamic performance of regenerative turbomachines, few have investigated the noise caused by the flow circulating in the pump. The present work aims to build reasonable models that could simulate the flow and noise performance of a regenerative automotive fuel pump. To achieve this objective, the CFD and CAA models were considered for the regenerative pump. For verifying the simulation results, the fluid and noise performance tests were applied. Accuracy of the simulations was assessed by comparisons to experimental data. This work was intended to lay the foundation for further study on the noise optimization of regenerative fuel pump.

\section{REGENERATIVE FUEL PUMP GEOMETRY}

The regenerative fuel tank-pump system consists of a fuel tank and a fuel pump module, plotted in Fig. 1. For CFD simulation, we just considered the flow domain in the fuel pump module, as shown in Fig. 2. Simplification was considered in the outlet domain, and the required pressure rise is $400 \mathrm{kPa}$ at a mass flow rate of $20.5 \mathrm{~g} / \mathrm{s}$. The regenerative fuel pump is operated at $6000 \mathrm{rpm}$, and the impeller has 47 blades with chevron blade angle of $30^{\circ}$. More detailed specifications are shown in Table I, and sectional view of the impeller in Fig. 3.

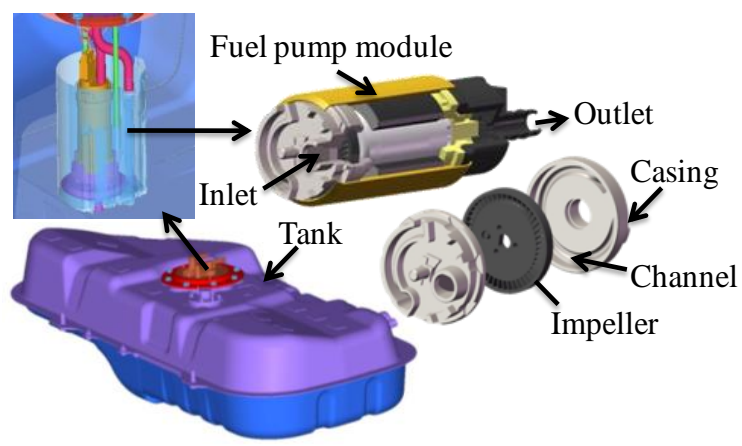

Fig. 1. Structures of the regenerative fuel pump-tank system.

\section{STEADY STATE FLUID DYNAMIC ANALYSIS}

For flow analysis in the regenerative fuel pump, this work used ANSYS CFX 15.0. Results were obtained by solving the three-dimensional RANS equations using a finite volume discretization method. The computational domain was obtained through SolidWorks, and ICEM-CFD was used to generate the computational meshes. ANSYS CFX-Pre, Solver, and Post were used to define the boundary conditions, solve the equations, and for post processing, respectively. A high-resolution scheme with second-order accuracy in space was used for the numerical scheme of the convection terms in the governing equations.

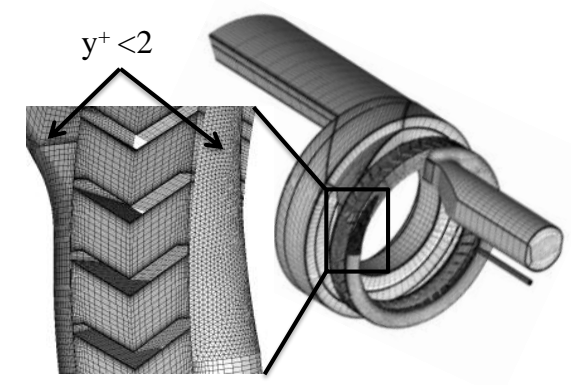

Fig. 2. CFD computational domain and grids.

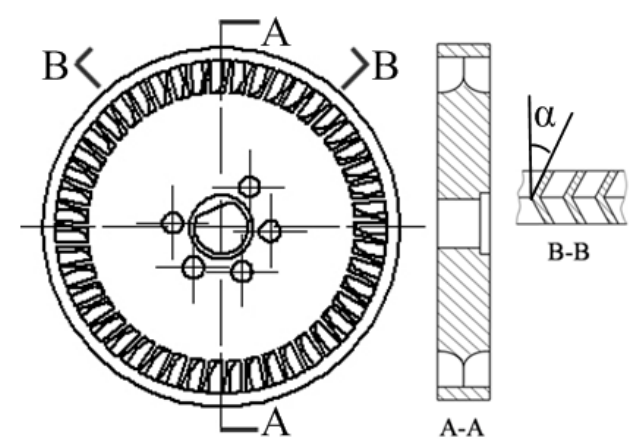

Fig. 3. Sectional view of the impeller.

TABLE I: DESIGN SPECIFICATIONS FOR THE REGENERATIVE FUEL PUMP

\begin{tabular}{cc}
\hline \hline Impeller thickness $(\mathrm{m})$ & 0.0038 \\
Impeller diameter $(\mathrm{m})$ & 0.0328 \\
Blade thickness $(\mathrm{m})$ & 0.0004 \\
Number of baldes $(\mathrm{EA})$ & 47 \\
Chevron blade angle $\alpha\left(^{\circ}\right)$ & 30 \\
Design mass flow rate $(\mathrm{kg} / \mathrm{s})$ & 0.0205 \\
Rotational speed $(\mathrm{rpm})$ & 6000 \\
Pressure rise $(\mathrm{kPa})$ & 400 \\
\hline \hline
\end{tabular}

This work used the k- $\omega$-based shear stress transport (SST) turbulence model for turbulence closure. The SST model solves a k- $\omega$ model in the wall region and a k- $\varepsilon$ model in bulk flow. Between these two models a blending function ensures a smooth transition. Bardina et al. [14] showed that the SST model more effectively captures recirculating flow under an adverse pressure gradient than other eddy viscosity models. The near-wall turbulence model used in ANSYS-CFX 15.0 switches between a low-Reynolds number model and an empirical wall function according to the $y+$ value of the first grid point from the wall. In the present simulations, by adjusting $\mathrm{y}+$ to be less than 2 as shown in Fig. 2, the low-Re version of the SST model, which adapts the low-Re k- $\omega$ model developed by Wilcox [15] in the near-wall region, was employed.

The computational domain for the numerical analysis consists of a rotating domain (impeller domain) and two stationary domains (inlet and outlet domains). Gasoline was considered as the working fluid. The total pressure $0 \mathrm{kPa}$ and $400 \mathrm{kPa}$ were assigned at the inlet and outlet domain 
respectively, and the rotating speed, $6000 \mathrm{rpm}$, was set to the impeller domain. The adiabatic and no-slip conditions were set at the solid surfaces in the computational domain. A frozen rotor method was used at the interface between the stationary and rotating domains in steady state computations.

All meshes in this work were created using the meshing program ICEM (ANSYS Inc.). For establishing grid independency, analysis was carried out with number of elements restricted to approximately 1 million, 2 million and 4 million elements containing hybrid hexahedral/tetrahedral grids, and the grids were refined at the wall region where the flow properties change rapidly. The mass flow rates of the three schemes and experiment are shown in Table II. Since the variation in the mass flow rate values was less than $1.2 \%$ for models containing elements greater than 1 million, mesh size of approximately 1 million was adopted to save the computational time, and relative discrepancy between experimental and computational results was $1.9 \%$.

TABLE II: GRID INDEPENDENCY TEST

\begin{tabular}{llllc}
\hline \hline Number of elements & 1092018 & 2122816 & 4137091 & Experiment \\
Mass flow rate (kg/s) & 0.02011 & 0.01999 & 0.01985 & 0.0205 \\
\hline \hline
\end{tabular}

\section{ACOUSTIC ANALYSIS}

\section{A. Unsteady State Fluid Dynamic Analysis}

Based on the steady RANS analysis, unsteady RANS analysis extracted fluid dynamic sources to analyze the acoustic characteristics of the regenerative fuel pump. In the unsteady computation, a transient rotor stator method was used at the interface between the stationary and rotating domains, the time step and coefficient loops for time scale control were set to $2.12766 \times 10^{-5} \mathrm{~s}$ and 10 times respectively in order to reduce all maximum residuals to a value below $10^{-5}$. This provided 10 time steps per impeller blade passage. Since the nature of flow is unsteady, it requires numerical analysis until the transient fluctuations of the flow field become time periodic as judged by the pressure fluctuations. In the present analysis this has been achieved after 5 complete rotations of the impeller. The pressure at the monitor points are recorded corresponding to each rotation of the impeller by time step advancement, as shown in Fig. 4 and Fig. 5. The data extracted from the fifth revolution will be used for the following acoustic analysis.

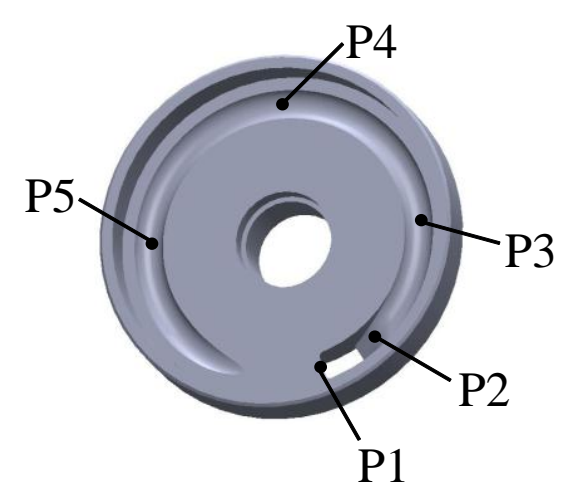

Fig. 4. Monitor points on the outlet channel.

The CFD approach is beneficial in the flow visualization to extend the knowledge of the flow physics. Fig. 6 represents the streamline of the gasoline circulating in the pump, the path lines plot indicates the helical or corkscrew motion that occurs within the pump. This coincides with the observation by Quail et al. [16].

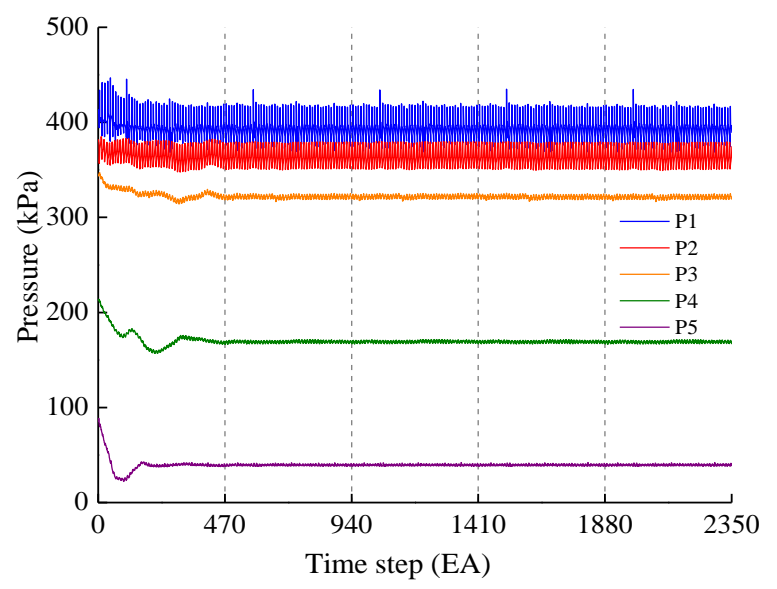

Fig. 5. Pressure fluctuations of monitor points.

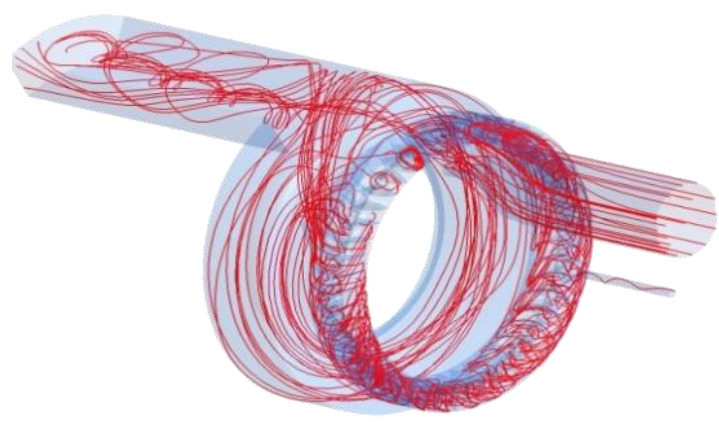

Fig. 6. Regenerative fuel pump helical path lines plot.

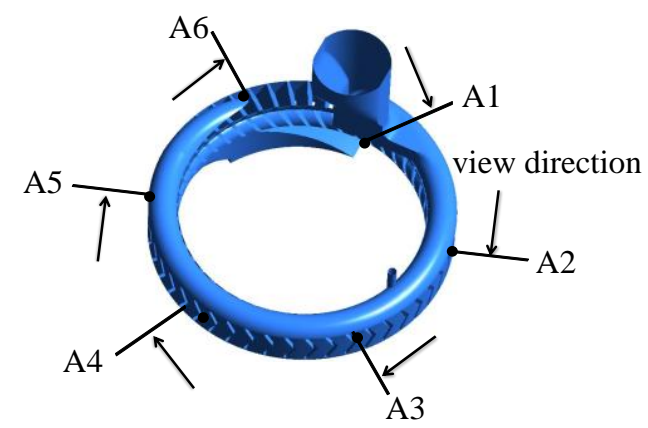

Fig. 7. Observation sections along the peripheral direction.

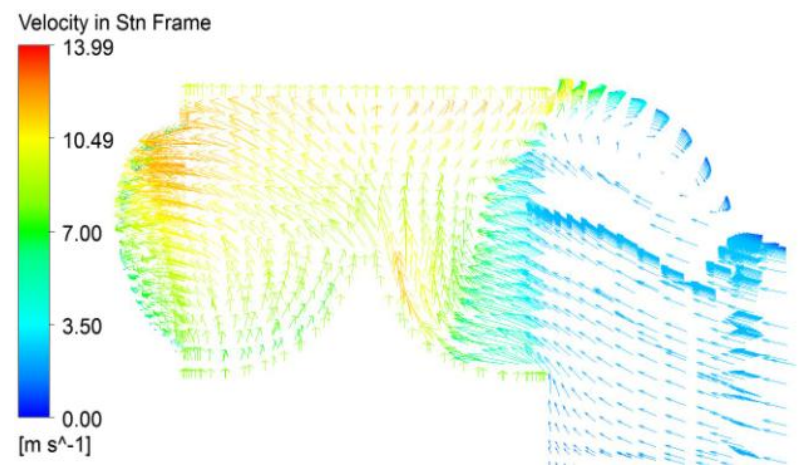

Fig. 8. A1 section.

Fig. 7 shows the observation sections along the peripheral direction. Fig. 8 to Fig. 13 show the fluid velocities evolution process. Velocities increase gradually from section A1 to A3, 
and do not change much until section A5, meaning that the fluid is fully developed during the region. After that, fluid velocities become to decrease, as the pressure is higher at the place near the outlet. It can demonstrate that the physical range of a pump operation is composed of five regions, namely inlet, acceleration, linear, deceleration, and exit region. The phenomena have been illustrated by Wilson [17] and Senoo [18].

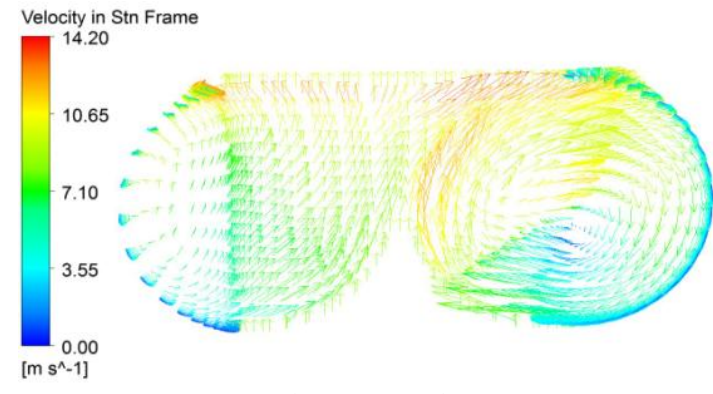

Fig. 9. A2 section.

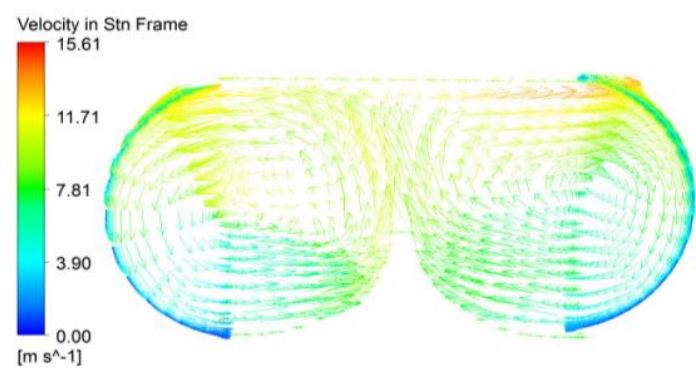

Fig. 10 A3 section.

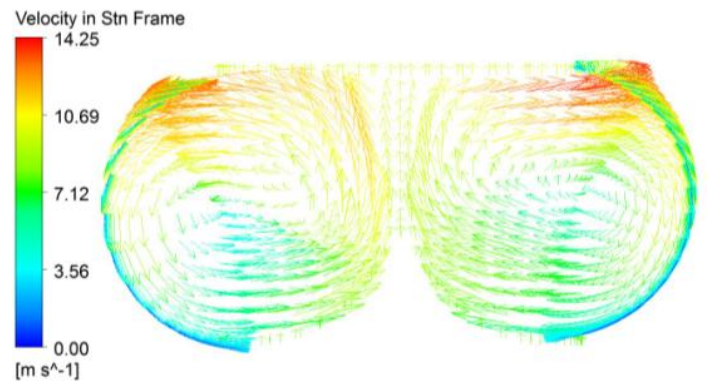

Fig. 11. A4 section.

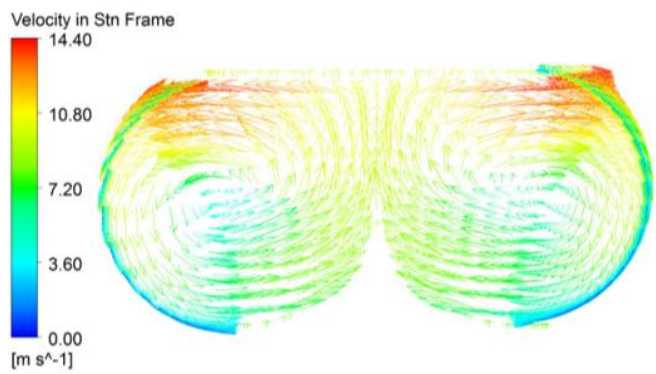

Fig. 12. A5 section.

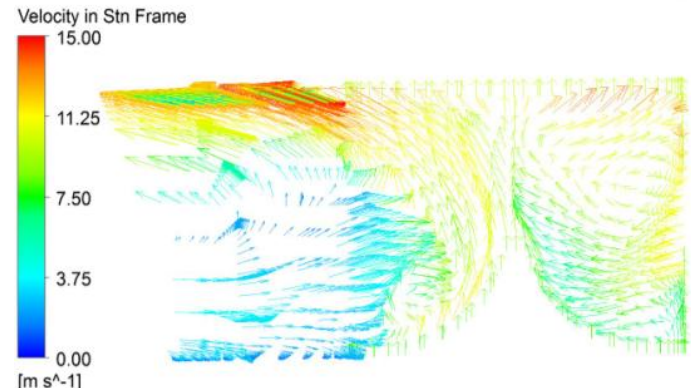

Fig. 13. A6 section.

\section{B. Acoustic Analysis}

In this work, acoustic analysis was implemented using finite/boundary element method, vibration-acoustic coupling method and Automatically Matched Layer (AML) method in LMS Virtual. Lab Rev12. In this process, the pressure fluctuations on the inner wall of the fuel pump extracted from the unsteady flow were used for acoustic analysis.

The mass and momentum conservation equations can be written as follow

$$
\begin{gathered}
\frac{\partial \rho}{\partial t}+\frac{\partial}{\partial x_{i}}\left(\rho v_{i}\right)=0 \\
\frac{\partial}{\partial t}\left(\rho v_{i}\right)+\frac{\partial}{\partial x_{j}}\left(\rho v_{i} v_{j}\right)=-\frac{\partial p}{\partial x_{i}}+\frac{\partial T_{i j}}{\partial x_{j}}
\end{gathered}
$$

where $\rho$ is the fluid density, $v$ the velocity, $T_{i j}$ Lighthill stress tensor. Combining these equations finds Lighthill's analogy [19] as

$$
\frac{\partial^{2} \rho}{\partial t^{2}}-c_{0}^{2} \nabla^{2} \rho=\frac{\partial^{2} T_{i j}}{\partial x_{i} \partial x_{j}}
$$

Ffowcs Williams and Hawings [20] extended equation (3) as follow

$$
\begin{aligned}
c_{0}^{2} \nabla^{2} \rho= & \left.\frac{\partial^{2} T_{i j}}{\partial x_{i} \partial x_{j}}-\frac{\partial}{\partial x_{i}} \mid p_{i j} \delta(f) \frac{\partial f}{\partial x_{j}}\right\rfloor \\
& +\frac{\partial}{\partial t}\left[\rho_{0} v_{i} \delta(f) \frac{\partial f}{\partial x_{i}}\right]
\end{aligned}
$$

In the right-hand side of equation (4) the three terms represent quadripole, dipole, and monopole sources respectively. For the regenerative fuel pump studied here, dipole source caused by the pressure fluctuations on the inner wall is the main acoustic source.

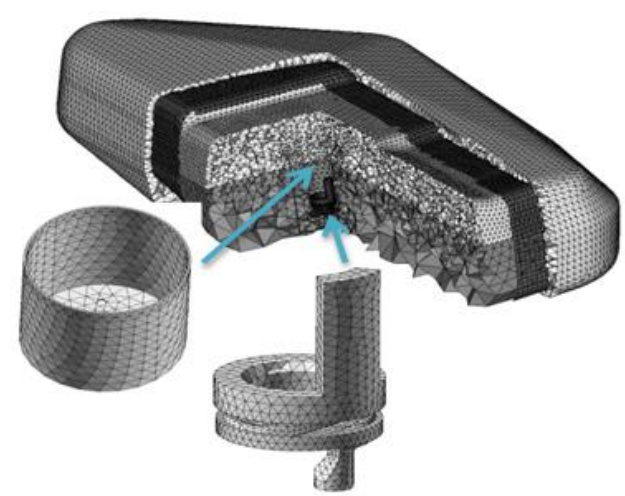

Fig. 14. Acoustic domain of the pump-tank system.

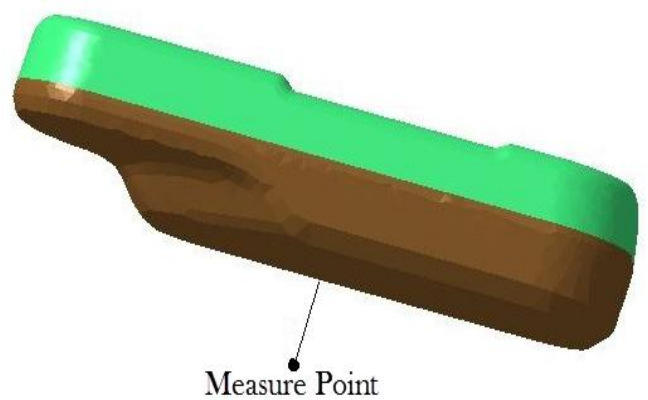

Fig. 15. Acoustic field point. 
Fig. 14 represents the whole acoustic domain for the acoustic analysis, which consists of pump boundary, oil pool boundary, air, gasoline and fuel tank domains. A tetrahedral grid system was constructed in the acoustic domain for acoustic analysis with approximately 136061 grid points to satisfy the target element length $(L \leqq c / 6 f$, where $c$ and $f$ indicate the speed of sound and maximum frequency value, respectively). An observer point is set to messure the sound pressure, which is $0.2 \mathrm{~m}$ below the fuel tank, corresponding to the measure position, as shown in Fig. 15.

\section{Experimental Validation}

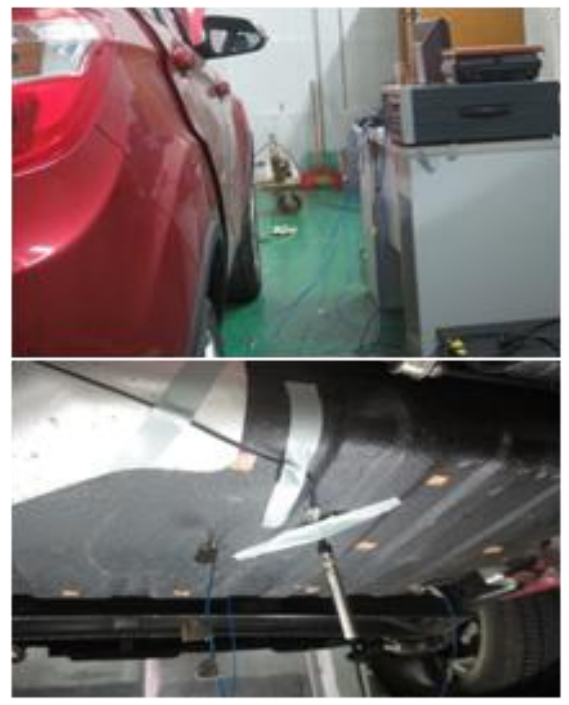

Fig. 16. Experimental set up and apparatus.

For validating the accuracy of the computational model, acoustic experiment of the regenerative fuel pump was implemented in the semi-anechoic room. The fuel pump was tested under installation condition, as shown in Fig. 16. The 40AK type microphone and 26AK type preamplifier together were used to measure the sound pressure, located $0.2 \mathrm{~m}$ below the fuel tank. The LMS SCADAS III system was used for data acquisition.

Fig. 17 represents the sound pressure levels comparison between computational and experimental results at the monitor point. As we just considered fluid induced noise, the blade passing frequency $(\mathrm{BPF}=\mathrm{RPM} \times \mathrm{N} / 60$, where RPM and $\mathrm{N}$ represent the rotational speed and blade number, respectively.) noise was the interest we had in the fuel pump. Mechanical noise caused by rotor misalignment and electromagnetic noise caused by DC motor commutators were not considered, which related to the basic frequency and harmonic frequencies corresponding to low and medium frequency range. So the simulational results were lower than experimental results under $3000 \mathrm{~Hz}$. Between 3000 and 4000 $\mathrm{Hz}$, sound pressure levels were higher in simulation than that in experiment, the probable reason was that some structures such as feed tubes, flange and damping layer were not considered. Similar trend between simulation and experiment was observed after $4000 \mathrm{~Hz}$, especially at the blade passing frequency(BPF) where SPLs were $45.38 \mathrm{~dB}$ and $47 \mathrm{~dB}$ respectively, with variation about $3.4 \%$. The regenerative fuel pump noise at high frequency, especially at BPF, is the main problem that the factories are facing, and the level exceeds the standard value. So the computational models established are reasonable to depict BPF noise performance of the regenerative fuel pump.

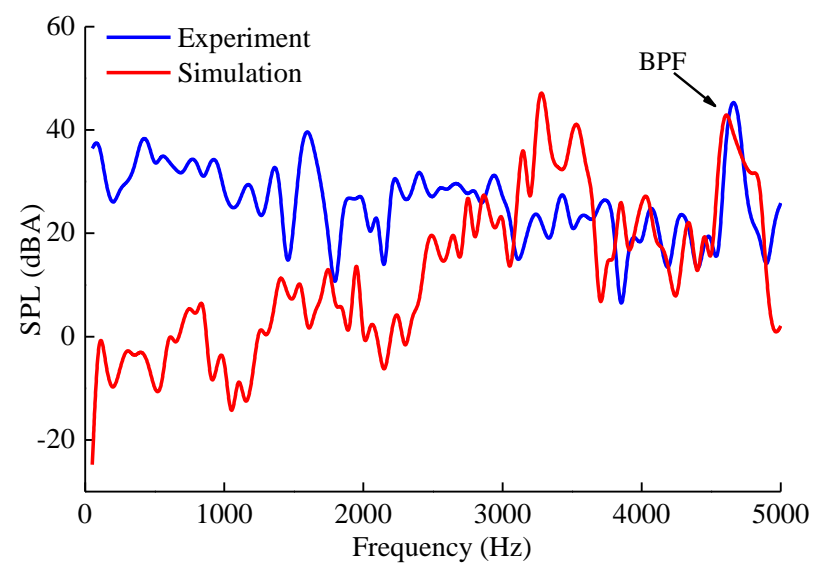

Fig. 17. Sound pressure level (SPL) comparison between simulation and experiment.

\section{CONCLUSION}

The numerical analysis using CFD helped understand the complex flow phenomena that exit in a regenerative pump. Three-dimensional steady and unsteady RANS analyses were carried out to investigate the fluid dynamic characteristics of the regenerative fuel pump, and the CFD results of the mass flow rate only had a relative discrepancy of $1.9 \%$ compared to experiment. The regenerative fuel pump innner wall pressure fluctuations extracted from the validated CFD model were used to implement the acoustic analysis, To verify the validity of the acoustic model, SPL test was carried out. The calculated sound pressure levels agreed well with experimental results at high frequencies, especially at blade passing frequency only a relative discrepancy of $3.4 \%$ existed. The technique and models established in this work could successfully capture the fluid dynamic and acoustic characteristics of the regenerative fuel pump, which would lay the foundation for studying noise optimization of the regenerative fuel pump.

\section{ACKNOWLEDGMENT}

This research was financially supported by the National Natural Science Foundation of China (Grant No. 51006010) and a joint China-UK research programme "111" (No. B12022).

\section{REFERENCES}

[1] Y. Teshome and E. Dribsa, "CFD study of the performance of regenerative flow pump (RFP) with aerodynamic blade geometry," M.S. thesis, University of Addis Ababa, Addis Ababa, Ethiopia, 2007.

[2] M. Badami, "Theoretical and experimental analysis of traditional and new periphery pumps," SAE Technical Paper Series, No. 971074, pp. 45-55, 1997.

[3] A. Engeda, "Flow analysis and design suggestions for regenerative flow pumps," Trans. ASME, FEDSM2003-45681, 2003.

[4] J. W. Song, A Engeda, and M. K. Chung, "A modified theory for the flow mechanism in a regenerative flow pump," Proceedings of the Institution of Mechanical Engineers, Part A: Journal of Power and Energy, pp. 311-321, vol. 217, 2003.

[5] M. M. Raheel, "A theoretical, experimental and CFD analysis of regenerative flow compressors and pumps for microturbine and automotive fuel applications," Ph.D. thesis, Michigan State University, East Lansing, MI, USA, 2003 
[6] I. S. Yoo, M. R. Park, and M. K. Chung, "Improved momentum exchange theory for incompressible regenerative turbomachines," Proceedings of the Institution of Mechanical Engineers, Part A: Journal of Power and Energy, pp. 567-581, vol. 219, 2005.

[7] F. J. Quail, M. Stickland, and A. Baumgartner, "A one-dimensional numerical model for the momentum exchange in regenerative pumps," Trans. ASME, vol. 133, pp. 093001-1-093001-7, 2011.

[8] K. V. Karanth, N. Y. Sharma, "CFD analysis of a regenerative pump for performance enhancement," in Proc. the 3rd World Conference on Applied Sciences, Engineering and Technology, Kathmandu, Nepal, 2014, pp. 344-349.

[9] M. Hübel, B. Blättel, and W. Strohl, "Investigation on fluid mechanics of the regenerative pump used in gasoline injection systems," $S A E$ Technical Paper Series, no. 950077, pp. 131-139, 1995.

[10] W. C. Choi1, I. S. Yoo, M. R. Park, and M. K. Chung, "Experimental study on the effect of blade angle on regenerative pump performance," Proceedings of the Institution of Mechanical Engineers, Part A: Journal of Power and Energy, pp. 585-592, no. 5, vol. 227, 2013.

[11] T. A.-M. Mekhail, O. M. Dahab, M. F. Sadik, M. M. El-Gendi, and H. S. Abdel-Mohsen, "Theoretical, experimental and numerical investigations of the effect of inlet blade angle on the performance of regenerative blowers," Open Journal of Fluid Dynamics, vol. 5, pp. 224-237, 2015.

[12] T. A. R. Rossetti, M. P. D. Passo, and F. B. Geremias, "Fuel pump module noise optimization through design of experiments," $S A E$ Technical Paper Series, no. 2013-36-0625, 2013.

[13] M. W. Heo, T. W. Seo, H. S. Shim, and K. Y. Kim, "Optimization of a regenerative blower to enhance aerodynamic and aeroacoustic performance," Journal of Mechanical Science and Technology, vol. 30, pp. 1197-1208, 2016.

[14] J. E. Bardina, P. G. Huang, and T. J. Coakley, "Turbulence modeling validation," in Proc. 28th AIAA Fluid Dynamics Conference, Fluid Dynamics and Co-located Conferences, Snowmass Village, CO,U.S.A., 1997.

[15] D. C. Wilcox, "Reassessment of the scale-determining equation for advanced turbulence models," AIAA Journal, vol. 26, pp. 1299-1310, 1988.

[16] F. Quail, T. Scanlon, and M. Stickland, "Design optimisation of a regenerative pump using numerical and experimental techniques," International Journal of Numerical Methods for Heat \& Fluid Flow, vol. 21, pp. 95-111, 2011.

[17] W. A. Wilson, M. A. Santalo, and J. A. Oelrich, "A theory of the fluid-dynamic mechanism of regenerative pumps," Trans. ASME, vol. 77, pp. 1303-1316, 1955

[18] Y. Senoo, "Influences of the suction nozzle on the characteristic of a peripheral pump and an effective method of their removal," Reports of Research Institute for Applied Mechanics, Kyusku University, pp. 129-142, vol. 3, 1954.
[19] M. Lighthill, “On sound generated aerodynamically," Proceedings of the Royal Society of London, Series A, Mathematical and Physical Sciences, pp. 564-587, vol. 211, 1952.

[20] J. E. Ffowcs Williams, and D. L. Hawkings, "Sound generation by turbulence and surfaces in arbitrary motion," Mathematical and Physical Sciences, vol. 264, pp. 321-342, 1969.

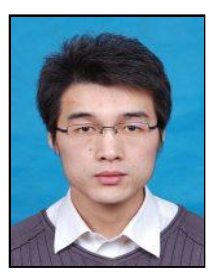

Ji-Fu Wang was born in Henan, China, in November 1987. He received his bachelor degree in engineering mechanics in 2010. He is currently pursuing his research towards Ph.D. degree in power machinery and engineering at Beijing Institute of Technology, China. His research interests include powertrain structural vibration and noise, fluid and noise performance of rotary machinery.

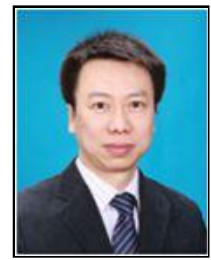

Hui-Hua Feng received his Ph.D. degree from Beijing Institute of Technology, China, in 2003. He is a Full Professor in the School of Mechanical Engineering of Beijing Institute of Technology, China. He focuses on the research of powertrain structural vibration and noise, fluid and noise performance of rotary machinery, and free piston engine linear generator.

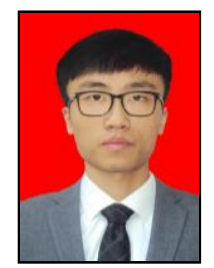

Yong-Xuan Huang graduated as a M.S. candidate from the School of Mechanical Engineering of Beijing Institute of Technology in 2016. He is working in Chongqing Changan Automobile Co., Ltd, China.

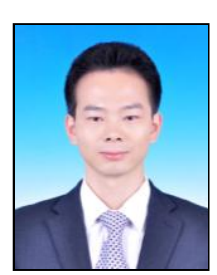

Xiao-Long Mou received his M.S. degree from Beijing Institute of Technology, China, in 2014. He is a Ph.D. candidate from the School of Mechanical Engineering of Beijing Institute of Technology. 